\title{
LA CONCEPCIÓN DE LA JUSTICIA EN LA OBRA TEORÍA DE LOS SENTIMIENTOS MORALES, DE ADAM SMITH
}

\author{
Carlos A. CaSAnOVa*
}

\begin{abstract}
RESUMEN: En este artículo se presentan en primer lugar las enseñanzas de la Teoría de los sentimientos morales referentes a la justicia. En particular se muestra: (1) que entrañan una pérdida de las distinción entre justicia general y justicia particular, por una parte; y entre justicia distributiva y conmutativa, por otra. (2) Que la pérdida anterior lleva a una "moralización" de la prudencia judicial y a una penalización del Derecho civil. Posteriormente se enmarca las enseñanzas sobre la justicia en concepciones smithianas más amplias, relativas a la acción y al orden del universo. Se contrastan brevemente además todas estas doctrinas con las enseñanzas griegas y romanas clásicas, metafísicas, antropológicas, de filosofía política, jurídica y moral.
\end{abstract}

Palabras clave: Adam Smith, justicia general, justicia particular conmutativa, justicia particular distributiva, Derecho civil, Derecho penal, libertad humana, naturalismo, mecanicismo.

ABSTRACT: This paper expounds, in the first place, the teachings of the Theory of Moral Sentiments concerning justice. Especially it asserts: (1) that such teachings involve the loss of the distinction between general and particular justice on the one hand, and between commutative and distributive justice on the other. (2) That such a loss results in a "moralization" of judicial prudence and a criminalization of civil law. Afterwards, Smith's teachings on justice are framed within some of his wider doctrines, which concern action and the order of the universe. Moreover, all these teachings are contrasted with classic Greek and Roman doctrines on metaphysics, anthropology, political philosophy, philosophy of law and morality.

Key words: Adam Smith, general justice, particular commutative justice, particular distributive justice, civil law, criminal law, human free will, naturalism, mechanism.

Se ha sostenido recientemente en Chile que Adam Smith representa una cierta continuidad con la concepción clásica de razón práctica, pero que su obra es más adecuada a la época moderna. Según la profesora Alejandra Carrasco, en efecto, el ilustrado escocés habría hecho progresar la ciencia moral más allá del punto donde la dejó Aristóteles. Como aspectos de tal progreso se mencionan (1) la introducción de los conceptos de universalidad e imparcialidad que permiten minizar los "presupuestos metafísicos" y prescindir del "conocimiento intuitivo" como precondición de los juicios morales; y (2) la subjetivación de la justificación moral, con la que se conquista el "preciado valor moderno de la autonomía".

\footnotetext{
* Profesor adjunto asociado de la Pontificia Universidad Católica de Chile, Director de Estudios IAP-PUC, Campus Oriente, Avenida Jaime Guzmán 3300, Providencia. Santiago de Chile. ccasanova@uc.cl

${ }^{1}$ Carrasco (2005) pp. 28-29, 32 y 35.
} 
En otro lugar hemos mostrado que es verdad que Smith es un nominalista que niega que tengamos intelecciones acerca de lo bueno inmerso en lo sensible. Pero también se mostró que él posee presuposiciones metafísicas de envergadura. Es, en efecto, un metafísico naturalista que sostiene que somos dirigidos de modo natural a nuestros fines y medios por instintos, no por razones. Allí mismo se ha dejado claro que Smith postula que la medida de la moral es en definitiva el hombre, y no Dios ${ }^{2}$. Es decir, el ilustrado escocés está más cerca de Protágoras que de Aristóteles. Hay que reconocer que en eso verdaderamente se aproxima al paradigma que muchos tienen en mente cuando hablan del "hombre moderno" 3 . En esta oportunidad no se tratará de hacer una exposición general de las doctrinas de Smith, sino presentar el profundo contraste que existe entre su concepción de la justicia y la teoría clásica, en particular la aristotélica ${ }^{4}$. En esta nueva tarea será preciso, sin embargo, enmarcar la concepción de la justicia en otros aspectos de las doctrinas smithianas que el propio autor ve como íntimamente conectados con aquella. De esta manera se mostrará en este punto particular que, a pesar de que el autor escocés usa a menudo el vocabulario del Estagirita, el significado que da a las palabras es radicalmente distinto.

Se irá en la exposición de lo más particular a lo más general. Es decir, se mostrará primero algunos casos de justicia conmutativa que Adam Smith explica de un modo claramente errado; se verá desde allí cuál es su concepción general de la justicia; se enmarcará tal concepción en la teoría de los actos del hombre; y se llegará finalmente a una rápida mirada acerca de su visión del cosmos. En cada uno de estos pasos será obvio el fuerte contraste con las enseñanzas clásicas.

\section{ALGUNOS CASOS DE JUSTICIA CONMUTATIVA}

En el capítulo 2 de la sección 3 de la Parte II de la Teoría de los sentimientos morales, Adam Smith trata de explicar la influencia de la fortuna en los castigos que de acciones dañinas exige la justicia. Desde tres casos recogidos allí se podrá mostrar el profundo error de enfoque que se da en las doctrinas smithianas.

Primer caso: "Nuestro resentimiento contra la persona que solo ha intentado causarnos un daño rara vez es tan fuerte como para arrastrarnos a infligirle el mismo castigo que habríamos pensado justo si él nos hubiera efectivamente dañado. En un

\footnotetext{
2 CASANOVA (2007).

3 La verdad es que en la Modernidad la mayor parte de los hombres sujetos a las repúblicas o tiranías occidentales han sido cristianos. TOCQUEVILlE (1953) mostró esto bastante bien en lo que se refiere a los Estados Unidos. Solo últimamente los secularistas están logrando, con una manipulación propagandística sin precedentes, ahogar la religiosidad en las mayorías o satisfacerla con sucedáneos indignos. La violencia de los comunistas es reconocida por todos los intelectuales honrados, que son minoría, lamentablemente. En cuanto a la violencia que se ha empleado en los Estados Unidos, el mejor estudio es el de JONES (2004).

${ }^{4}$ En la exposición de las doctrinas clásicas no se dará referencias detalladas para cada afirmación. Los principales textos en que se basará este artículo son los siguientes: PLATÓN, Teeteto y Leyes IV (716c-e) y X; Aristóteles, Ética a Nicómaco (en especial libros III, V y X); CICERón, Tópicos; GAYO, Institutas; SANTO Tomás de Aquino, In Decem Libros Ethicorum Expositio, Summa Theologiae I-II y II-II; VILLEY (1969 y 1981); VIEHWEG (1964).
} 
caso, la alegría de nuestra liberación alivia nuestro sentido de la atrocidad de su conducta; en el otro, la pena de nuestro infortunio lo acrecienta. Su demérito real, sin embargo, es sin duda el mismo en ambos casos, puesto que sus intenciones son igualmente criminales; y hay en este aspecto, entonces, una irregularidad de sentimientos de todos los hombres y, según pienso, una consiguiente relajación de la disciplina de las leyes de todas las naciones, de las más civilizadas y de las más bárbaras. La humanidad de un pueblo civilizado dispone que en estos casos o no se castiguen las malas acciones o que se mitiguen los castigos, cuando su indignación natural no es agravada por las consecuencias del crimen. Los bárbaros, de otra parte, cuando no se ha seguido consecuencia real alguna de una acción cualquiera, no están muy inclinados a ser delicados o curiosos acerca de los motivos" (parágrafo 4).

Segundo caso: "Cuando la negligencia de un hombre ha ocasionado un daño a otro sin intención, generalmente entramos en el resentimiento del que lo sufre hasta el punto de aprobar que inflija un castigo al ofensor mucho más lejos de lo que la ofensa habría parecido merecer, si no se hubiera seguido de ella una tan desafortunada consecuencia" (parágrafo 7).

Tercer caso: "Así, por la Ley Aquilina, el hombre que no ha podido controlar un caballo que por accidente se ha asustado, tendrá que compensar el daño si atropella el caballo al esclavo de su prójimo. Cuando ocurre un accidente de este tipo, nos inclinamos a pensar que el hombre no debió haber montado semejante caballo y que haberlo intentado fue una ligereza imperdonable, aunque si no hubiera ocurrido el accidente no solo no habríamos hecho tal reflexión, sino que habríamos tenido el no querer montarlo como un efecto de tímida debilidad y de ansiedad por acontecimientos meramente posibles a los que es inútil prestar atención” (parágrafo 10). Antes y después afirma Adam Smith que en tal caso la compensación que ha de dar el dueño del caballo es un “castigo" (parágrafo 9), pues a causa del infortunio del daño producido ha de darse algún tipo de "expiación” (“atonement": parágrafo 10).

\section{A) Principios a CUYA LUZ AdAM SMith CONSIDERA lOS TRES CASOS}

Los capítulos 1 y 2 y la introducción de la sección 3 de la Parte II están basados en la presuposición de que el mérito y el demérito consisten en una "retribución", un castigo o un aplauso o premio, fundada en pasiones de resentimiento o de gratitud (capítulo 1, parágrafo 1). Estas pasiones se dirigen hacia un objeto y se pueden fundar en tres elementos: el objeto ha de ser causa de placer o de dolor; ha de ser capaz de sentir el mismo placer o dolor; y debe actuar movido por un plan (capítulo 1, parágrafo 6). Algunos objetos excitan la pasión por el primero solo de estos elementos, como la espada que guardamos porque sirvió para librar una importante batalla que aseguró la libertad de la Patria. Otros a causa de los dos primeros de estos elementos, como el animal que ha matado a un amigo. Otros, en fin, a causa de los tres elementos, como los seres humanos a quienes debemos un servicio o que nos han infligido un daño. Solo el tercer grupo de objetos excita de modo perfecto estas pasiones y, por lo mismo, recibe con propiedad el premio o el castigo. A veces, sin embargo, no se requiere el dolo para que una persona sea castigada con razón, sino que basta la culpa, la negligencia, por ejemplo. 
La justicia de los jueces sería en esta concepción la aplicación forzada de los castigos debidos, no de los premios. Una aplicación coactiva de la gratitud sería generalmente "impropia". Si se guarda esto en mente, de los párrafos anteriores es fácil colegir ahora que Adam Smith ignora del todo una distinción capital elaborada por Aristóteles, recibida por Cicerón y -a través de él- por el Derecho Romano, y rescatada en nuestros días por Michel Villey.

\section{B) LA DISTINCIÓN CLÁSICA ENTRE JUSTICIA GENERAL Y JUSTICIA PARTICULAR, DISTRIBUTIVA Y CONMUTATIVA}

La justicia general abarca toda virtud en cuanto tiene que ver con otros hombres. Es la justicia como virtud cardinal, presente en toda otra virtud. Pero hay, además, una virtud particular cuyo opuesto es la avaricia y que tiene que ver con los repartos o los intercambios de bienes exteriores. Por no referirse a las pasiones, sino a las acciones que tienen por objeto bienes exteriores, a diferencia de lo que ocurre en la templanza y la fortaleza, el medio de esta virtud no está en el agente, sino en las cosas. Esta es la razón por la que el cumplimiento de las obligaciones conectadas con la justicia puede ser exigido ante un tribunal. Pero la justicia particular se divide a su vez en distributiva y conmutativa. La primera se refiere a los criterios de reparto de los bienes que toda sociedad establece, según una cierta jerarquía de dignidades. La segunda es la igualdad que debe darse en las transacciones particulares, suponiendo desde luego los repartos de la justicia distributiva. Es sobre esta sobre la que se discute en los tribunales ordinarios ${ }^{6}$. Cuando un caso va a un tribunal, lo que las partes buscan normalmente no es ya la rectitud moral de la contraparte, sino que se reconozca el medio real de la justicia y que se le den las cosas que en Derecho les corresponden. El Derecho en cuanto saber de los jueces es, por ello, el humilde pero indispensable servidor de la igualdad en las transacciones, no el censor moral de la rectitud de intención.

\section{C) CONTRASTE ENTRE LA PERSPECTIVA CLÁSICA Y LA SMITHIANA}

Si con estas distinciones en mente se vuelve los ojos otra vez a los textos de Adam Smith antes transcritos es posible fácilmente percibir el desconocimiento que delatan. Smith concibe la función del juez como si fuera la de un censor moral. Esto es muy probablemente consecuencia de su formación en la tradición calvinista (presbiteriana) que, como la mayoría de los protestantes, despreció los saberes clásicos como cosa de los "gentiles" y "papistas". Los calvinistas y sus sucesores secularizados de la Ilustración concebían la sociedad de una manera en parte nominalista y en parte "judaizante" en el sentido de las cartas de san Pablo7. Ya no era el ius real lo que podía guiar las acciones

\footnotetext{
5 Ver Parte II, Sección 2, capítulo 1.

${ }^{6}$ Los tribunales constitucionales pueden conocer controversias de otra índole.

7 Adam Smith realizó en sí mismo esta sucesión del calvinismo a la Ilustración. De hecho, en la primera edición de la Teoría de los sentimientos morales aún incluía al final del capítulo 3 de la sección 2 de la parte II un pasaje en que reconocía que el Cristianismo era fruto de una revelación divina. Ese pasaje fue suprimido en la sexta edición. Decía así: "The doctrines of revelation coincide, in every respect, with those original anticipations of nature; and, as they teach us how little we can depend upon the imperfection of our own virtue, so they show us, at the same time, that the most powerful intercession has been made, and that the most dreadful atonement has been paid for our manifold transgressions and iniquities".
} 
del magistrado, sino la ley. Ya no era la igualdad o equidad en las transacciones lo que quería lograr el juez, sino la "rectitud legal". Veamos.

En el primero y segundo casos transcritos es fácil ver desde una perspectiva clásica que si alguien no nos causa un daño civil, entonces no tiene nada que reparar desde el punto de vista del Derecho civil. Por esto, el mero intento de causar el daño no puede dar lugar a una indemnización. Esto se explica no porque nuestro "sentimiento de indignación" sea menor, sino sencillamente porque no se ha afectado la igualdad en las transacciones. Puesto que no hemos sido privados injustamente de ninguna cosa, nadie está obligado a reparar nada.

Si, sin embargo, todavía en el primer caso considerado por Adam Smith, lo que se ha intentado es un delito ${ }^{8}$, entonces hay que establecer varias distinciones. En el Derecho penal, el castigo busca primero que nada retribuir al delincuente un mal a cambio del bien que injustamente y en detrimento de otros o del bien común se ha procurado. Pero también intenta dar una pena proporcionada al criminal, de modo que él no vuelva a delinquir en el futuro (porque se verá físicamente impedido de ello y porque luego tendrá miedo de reincidir), de modo que otros también tengan temor de delinquir y de modo que la indignación pública sea aplacada y se eviten reacciones violentas. Como puede percibirse, en esta área del Derecho por persona agraviada puede tenerse a la víctima o a la república. Por ello el delito puede ser de acción privada o de acción pública. La jerarquía de penas, en todo caso, tocaría establecerla a las autoridades encargadas de la justicia distributiva. El juez solo tendría que velar por que a un reo se le "diera" la pena debida a su delito.

Ahora bien, la tentativa de cometer un delito puede ya merecer la aplicación de una pena9. Pero "merecer" aquí significa que al reo le toca, de acuerdo con los criterios de justicia distributiva, recibir un determinado "mal" exterior. En el Derecho penal, como se ve, las enseñanzas de Smith pueden ser verosímiles hasta cierto punto. Tanto porque la conducta y la intención pueden merecer una determinada pena, como porque es verdad que la severidad de la pena tiene también que ver con la indignación pública que un delito pueda producir, como se ha visto. Sin embargo, hay incluso en esta área una diferencia no pequeña entre la concepción clásica y la smithiana, en lo que se refiere

\footnotetext{
${ }^{8}$ El segundo caso es diferente, en la perspectiva del Derecho penal. Normalmente la simple culpa (por oposición al dolo: es decir, la imprudencia, impericia o negligencia) no constituye delito si no tiene consecuencias.

${ }^{9}$ En la teoría clásica del Derecho, la tentativa podía merecer una pena porque era un acto voluntario y libre. La tradición utilitarista y empirista tratará de aplicar "medidas de seguridad" a "sujetos peligrosos" (por razones biológicas o sicológicas) sin que hayan realizado ningún acto voluntario. Adam Smith no proporciona herramientas teóricas suficientemente poderosas para detener esta tendencia. Los "sentimientos", en efecto, tienen una clara base orgánica que permitiría a los empiristas justificar un biologicismo del tipo de Daniel Dennett, por ejemplo. Las medidas de seguridad podrían incorporarse a la tradición clásica, pero solo con la condición de que a los índices de "peligrosidad" se una algún tipo de acción voluntaria que justifique la aplicación de la medida. (Tal acto debería ser un cuasidelito, tal como la tentativa inidónea). Esto ha de exigirse porque la voluntad humana no tiene órgano corpóreo y, por ello, ni las acciones futuras pueden predecirse con exactitud, ni es, en principio, conforme a la dignidad del hombre que su libertad física sea restringida sin que él haya incurrido en un delito o cuasidelito.
} 
a la determinación y gradación de las penas. Tal diferencia se mostrará más tarde en este mismo artículo.

Considérese ahora el tercer caso, que es claramente de Derecho civil. Se trata, en efecto, de la responsabilidad objetiva por animales. Adam Smith no ve en absoluto la diferencia con los casos previos, y concibe el asunto como si fuera penal. Es decir, Smith penaliza el Derecho civil, y lo hace no por un accidente, sino como una consecuencia necesaria de su "sistema de filosofía moral y política".

Adam Smith, en efecto, dice que la indemnización dada por el dueño a quien sufre el daño causado por un caballo es una suerte de "expiación" o "castigo". Añade que el fundamento de dicho castigo sería una cierta "culpa" o "negligencia". Sostiene también que nuestra indignación contra el dueño, que es la causa eficiente del castigo, se debe al dolor que ha infligido a otro. Si la misma acción exactamente del dueño no hubiera resultado en daño para nadie, no sentiríamos indignación contra él. Entonces, concluye, esta indignación es claramente influida por la fortuna, con lo cual queda claro que la fortuna afecta el demérito, puesto que afecta el sentimiento de indignación del que aquel depende ${ }^{10}$. No cabe duda, pues, de que Adam Smith penaliza una institución que pertenece al Derecho civil y que nada tiene que ver con "castigos". De lo que se trata aquí es de la responsabilidad objetiva por animales, y lo que está en juego no es un castigo, sino una indemnización. Lo que se pretende no es corregir al dueño del caballo, que para nada ha incurrido en culpa, pues si hubiera incurrido en culpa sería responsable por otro título. Lo que se pretende es restaurar la igualdad en las transacciones involuntarias ${ }^{11}$.

La confusión que conduce a penalizar el Derecho civil puede apreciarse con claridad en otro texto, de la Parte VI, sección 2, introducción, parágrafo 2:

El resentimiento apropiado por la injusticia intentada o cometida de hecho es el único motivo que puede justificar el que dañemos o perturbemos la felicidad de nuestro prójimo en cualquier respecto, a los ojos del espectador imparcial. Hacerlo por cualquier otro motivo es en sí mismo una violación de las leyes de la justicia, frente a la que debería usarse la fuerza bien sea para impedirla o para castigarla. La sabiduría de todo Estado o república (commonwealth) procura emplear la fuerza de la sociedad para retraer del mejor modo posible a aquellos que se encuentran bajo su autoridad de que unos a otros se hagan daño o perturben su

\footnotetext{
10 Sobre esto último trata toda la sección 3.

11 Hay diversas explicaciones teóricas acerca del fundamento de la responsabilidad objetiva tal como fue expandida por la jurisprudencia francesa durante el siglo XIX. Varias se han convertido en principios tópicos con los que pueden iluminarse los casos concretos que han de decidir los jueces. Así, por ejemplo, tenemos la teoría de la equidad, según la cual no hay razón para que sea la víctima y no el dueño quien soporte el daño; y puesto que el dueño probablemente tenga más medios económicos que la víctima (en los casos considerados por la jurisprudencia francesa, no necesariamente en los casos previstos en el Derecho romano), es mejor que en general sea el dueño quien soporte el daño. Otra teoría es la del riesgo: quien introduce en la sociedad un objeto riesgoso debe cargar con los daños que ese objeto pueda causar fortuitamente. Ninguna de estas teorías supone que el pago se trate de un castigo. Todas saben y presuponen que es una indemnización.
} 
felicidad. Las reglas que establece para este propósito constituyen el Derecho civil y penal de cada particular estado o país.

En el fondo del error señalado en la calificación de la naturaleza de la indemnización se encuentra un problema teórico de más envergadura. Adam Smith pertenece a la tradición metafísica nominalista y por ello piensa que la justicia judicial no es fruto en primer lugar de la prudencia de los magistrados puesta al servicio del ius, sino fruto de los sentimientos de los hombres. Puesto que el ius o justo medio real es una medida inteligible que solo puede captarse intelectivamente, Smith no puede aceptar que ninguna parte del Derecho, ni la civil ni la penal, tenga tal "fundamento". Necesita, por tanto, transformar la naturaleza del arte judicial, que ya no puede concebirse como una disciplina prudencial (en el sentido amplio que tenían la frónesis griega y la prudentia romana o cristiano-latina), sino como una mera "aplicación de reglas", de máximas cuyo origen sería sentimental. Este tema merece un examen más detallado.

\section{LA CONCEPCIÓN GENERAL DE LA JUSTICIA EN ADAM SMITH}

Es preciso corroborar en primer lugar el carácter nominalista de Adam Smith. No es esta una tarea muy difícil pues ese carácter se manifiesta a cada paso. Hemos escogido un aspecto de las doctrinas del ilustrado escocés que resulta muy significativo.

Una consecuencia del nominalismo desde los tiempos en que Guillermo de Ockham decidió enfrentarse al Papa Juan XXII es que se conciba el origen de la sociedad como un contrato voluntario precedido por un período de tiempo en que reinaba el “individuo". Adam Smith acepta de modo explícito esta visión de la sociedad. "Entre iguales, se considera que cada individuo está naturalmente, y previo a la institución del gobierno civil, dotado de un derecho de defenderse a sí mismo de injusticias y de infligir un cierto grado de castigo a aquellos que han cometido injusticia contra él”. Pero no puede usarse la fuerza para exigir un acto de gratitud o beneficente, esto no sería "natural". Sin embargo, una vez establecida la comunidad civil, los magistrados pueden, con vistas a promover la prosperidad de la república [commonwealth], establecer castigos para el caso de que se descuide uno de estos deberes. Tales castigos serían de mero "Derecho positivo"12. Este modo de integración de los derechos naturales con el "Derecho positivo" es también un indiscutible descendiente de las doctrinas ockhamistas en las que, por primera vez desde los sofistas griegos, se establecía una separación neta entre la justicia que aplicaban los magistrados y unos supuestos "derechos naturales" que eran independientes de la comunidad. Es claro, pues, que Smith se encuentra inscrito en la tradición nominalista de pies a cabeza ${ }^{13}$.

Conforme a lo ya visto, Adam Smith piensa que la justicia consiste simplemente en que no nos dañemos unos a otros: "la mera justicia es, en la mayoría de los casos, una

12 Parte II, sección 2, capítulo 1, parágrafos 7-8.

13 No me detengo en este punto porque he hecho una exposición sumaria del nominalismo en Derecho y en teoría política en el artículo CASANOVA (2005). 
virtud puramente negativa, y solo nos aparta de dañar a nuestro prójimo"14 . La justicia no puede exigir que se dé la gratitud debida a un benefactor. La ingratitud no produce resentimiento sino que de modo natural produce solo "odio" ${ }^{15}$. En la línea del nominalismo, pero con la adición de un naturalismo "ilustrado", Smith va a sostener que lo que guía el vivir justo o, sobre todo, la defensa judicial de la justicia, no es la prudencia, sino un instinto. Lo que nos mueve a vivir con justicia es tanto el ansia de autoaprobación como el evitar el remordimiento, ambos "sentimientos naturales" en su esencia ${ }^{16}$. La protección natural de la justicia es el "resentimiento" que una injuria provoca en la víctima y en los espectadores. Pero ha de recordarse que este sentimiento nos fue dado por la naturaleza para nuestra defensa, y solo para la defensa ${ }^{17}$.

La consecuencia natural del resentimiento es el castigo, que puede infligirse en el acto mismo de repeler una agresión, o posteriormente ${ }^{18}$. "Como obra todo hombre, así deberá obrarse con él. La retaliación parece la gran ley que nos ha dado la Naturaleza"19. La Naturaleza nos ha dado un resentimiento instintivo, y la satisfacción de este instinto nos da la medida exacta del castigo. Es este movimiento instintivo el quicio y la esencia de todo el sistema jurídico. Las acciones que deben ser sancionadas y la medida del castigo no tienen otra regla ${ }^{20}$. De acuerdo con las doctrinas clásicas, donde se acepta que hay intelecciones de bienes inteligibles reales (en particular de las exigencias del bien común), la imposición de castigos y su gradación depende de juicios prudenciales de justicia distributiva. Hay, pues, un abismo en este punto entre las concepciones smithianas y las clásicas. Ese abismo es tan hondo como entre quien acepta que hay verdad práctica y por tanto en esta materia la medida es Dios y no el hombre, por una parte; y quien postula que no hay verdad práctica y por tanto en esta materia la medida es el hombre, por otra. Mas ahora no es posible entrar a mostrar este punto.

Insistamos en que un resentimiento que sea conforme a las reglas de la propiedad moral, y el consecuente castigo, se dirigen solo a quien falte contra la justicia:

\footnotetext{
${ }^{14}$ Parte II, sección 2, capítulo 1, parágrafo 9.

15 Parte II, sección 2, capítulo 1, parágrafos 1-5. En la parte VII, sección 2, capítulo 1, I (parágrafo 10), Adam Smith distingue entre la "justicia conmutativa" y la "distributiva". Luego dice que la primera es la que ha explicado en el cuerpo del libro (en las Partes II y VI, como hemos visto). Por la segunda entiende lo que en el cuerpo del libro ha llamado "beneficencia" acorde con las reglas de la propiedad moral. La justicia distributiva, así entendida, no debe estar sujeta a la coacción estatal (Parte VI, Sección 2, Capítulo 1, parágrafos 2 y 20). Añade luego que hay todavía otro sentido más amplio de justicia por el que se llama "injusto" a quien viola un aspecto cualquiera de la moral. En este pasaje Smith parece aproximarse a las distinciones clásicas a que hemos aludido, pero -en realidad- sigue dando a las palabras un sentido profundamente distinto.

Friedrich Hayek parece haber fundado su rechazo de la justicia distributiva en las explicaciones que Adam Smith da de ella en este pasaje. HAYEK (1980a) pp. 3, 4, 14, 21-22, 23; HAYEK (1980b) p. 107; HAYEK (1976) pp. 42, 79-80, 109-111; HAYEK (1960) pp. 94 y ss.; HAYEK (1981) pp. 154-156.

16 Por ejemplo, parte III, capítulo 3, parágrafo 4; y parte II, sección 2, capítulo 2, parágrafo 3.

17 Parte II, sección 2, capítulo 1, parágrafos 1-5.

18 Parte II, sección 2, capítulo 1, parágrafo 5.

19 Parte II, sección 2, capítulo 1, parágrafo 10.

${ }^{20}$ Parte II, Sección 1, capítulos 1, parágrafo 6; y 5, parágrafo 10.
} 
Y sobre esto se basa esa importante distinción entre la justicia y todas las otras virtudes sociales, sobre las que ha insistido mucho últimamente un autor de grande y original genio ${ }^{21}$, que nos sentimos bajo una obligación más estricta de actuar de acuerdo con la justicia, que, sin duda, de actuar conforme a la amistad, la caridad o la generosidad; que la práctica de las últimas virtudes mencionadas parece haberse librado a nuestra propia elección, pero que, de un modo o de otro, nos sentimos de una manera especial vinculados, atados y obligados a observar la justicia. Es decir, sentimos que la fuerza puede usarse con total propiedad y con la aprobación de todo el género humano para forzarnos a observar las reglas de esta virtud, pero no las de las otras 22 .

Como se ve, Smith todavía sabe que hay una diferencia importante entre la justicia y las demás virtudes, pero ya no sabe todo lo que ella entraña. La razón es que la concibe de un modo nominalista, legalista y naturalista. Es decir: (1) no acepta o ni siquiera sabe que hay un ius real que puede ser objeto del conocimiento del juez. (2) Por lo mismo, piensa que la justicia consiste en la observancia de reglas de conducta o en la imposición de castigos en caso de inobservancia. (3) Pero, a diferencia de los calvinistas, ya no cree que tales reglas vengan de una revelación divina, sino que postula que proceden de las reacciones de los hombres ante diversos escenarios o estímulos, reacciones que tienen una base natural, aunque sean socialmente modeladas, y que consisten en sentimientos y cristalizan en actos externos ${ }^{23}$. De los señalados defectos básicos en el análisis de los fenómenos judiciales ( 1 y 2) se siguen graves cortocircuitos. Entre ellos, los ya estudiados en torno a la justicia conmutativa o el que Adam Smith confunda la legítima defensa con un castigo ${ }^{24}$.

Que Smith intente suplir el vacío dejado por el nominalismo con un craso naturalismo es algo que ya se ha sugerido. Pero no puede mostrarse de modo adecuado haciendo alusión solo a la teoría de la justicia. Es preciso enmarcar esta en la teoría general de la acción humana y de la sociedad.

${ }^{21}$ De acuerdo con RAPHAEL y MACFIE (1984) p. 80 (nota), Adam Smith se refiere aquí a Henry Home, Lord Kame.

22 Parte II, sección 2, capítulo 1, parágrafo 5.

23 Por supuesto, si Smith ha perdido, como ya observamos, la distinción entre la justicia particular y la general, con mucha más razón ha perdido la distinción entre la justicia conmutativa y la distributiva. Aunque aluda a ella en otra parte de la Teoría de los sentimientos morales, le da un sentido profundamente alejado del clásico. En efecto, allí la justicia conmutativa sería simplemente la voluntad de refrenarse de dañar al prójimo en su persona, reputación o posesiones, mientras la justicia distributiva consistiría en dar a nuestro prójimo todo el amor, respeto y estima que resulte apropiado conforme a su carácter, situación y conexión con nosotros. Según estos pasajes, solo el primer tipo de justicia podría exigirse coactivamente. (Cfr. Theory of Moral Sentiments, parte VI, sección 2, capítulo 1, parágrafos 2 y 20; y parte VII, sección 2, capítulo 1, parágrafos 9-10).

${ }^{24}$ Parte II, sección 2, capítulo 1, parágrafo 5, ya citado. En realidad, la legítima defensa nada tiene que ver con un castigo. Para comprenderlo, baste pensar en este ejemplo: un policía juzga erróneamente que Juan va a matar a Pedro. Para evitarlo, apunta su arma contra Juan con intención de matarlo. Este se da cuenta y no tiene más camino para salvar su vida que disparar antes al policía que, sin embargo, es inocente. 


\section{LA TEORÍA DE LA JUSTICIA ENMARCADA EN LA CONCEPCIÓN DE LOS ACTOS HUMANOS Y DE LA SOCIEDAD}

En otro lugar ya se ha expuesto con detenimiento que las doctrinas antropológicas de Adam Smith excluyen el libre arbitrio ${ }^{25}$. Aquí no se repetirá todo el análisis, sino que solo se mostrará cómo en la parte de su obra que expone las enseñanzas sobre la justicia se repiten y realizan las enseñanzas generales.

Smith sostiene que todo hombre está encomendado a su propio cuidado. Entonces, la prudencia consiste en buscar sobre todo la propia felicidad, es decir, la propia riqueza y los propios honores por encima de los del prójimo. Esto es "natural", y en la carrera por tal felicidad el individuo hace bien en correr con la mayor velocidad posible para derrotar a sus competidores ${ }^{26}$. Sin embargo, la justicia nos exige que no dañemos al prójimo en lo más mínimo, ni siquiera para alcanzar nuestra felicidad más cumplida o para evitar nuestra total ruina. En efecto, aunque "todo hombre es el mundo entero para sí mismo", para el resto de los hombres o para el espectador imparcial no tiene mayor importancia que ningún otro ser humano ${ }^{27}$.

\section{A) INDIVIDUALISMO Y NATURALISMO DEONTOLÓGICO}

Es fácil percibir en la doctrina de Adam Smith un individualismo muy marcado, con el complemento de un sentido fuerte de que uno es "correcto". En esto parece el escocés un claro descendiente del calvinismo, que permitía, según la anécdota recogida por Max Weber, que a un "cristiano" le costara entender lo que estaba mal en la oración del fariseo en la parábola del fariseo y el publicano ${ }^{28}$. A este personaje solo le importaba su propia salvación, y se tenía a sí mismo por justo y tenía a los demás por pecadores. En Smith la salvación ahora ha sido secularizada: se trata de la "felicidad" intramundana de los utilitaristas. Pero la justicia se ha desgajado de ella. Lo correcto y lo bueno ya no son lo mismo, como tampoco lo son en las doctrinas de Kant ${ }^{29}$. Por otra parte, Adam Smith no parece considerar ni la amistad ni sociedad intermedia alguna, entre el individuo y el Estado. Para un espectador, la felicidad de un hombre vale tanto como la de cualquier otro, diría el escocés. Se pasa por alto, al menos en este pasaje, que no es así. Que de ordinario la felicidad de un amigo o de los miembros de nuestra familia o de otra comunidad menor nos incumbe más que la de los otros miembros de la sociedad política.

Puesto que lo bueno ahora se concibe de modo individualista, y puesto que se concibe además como opuesto a lo correcto, la justicia ya no es un fruto de la amistad civil. Es, más bien, un mero límite a los apetitos. Un límite impuesto por el sentido del deber que es protegido por un sentimiento o deseo que es el más radical en los hombres

\footnotetext{
25 CASANOVA (2007).

26 Parte II, sección 2, capítulo 2, parágrafo 1.

27 Parte II, sección 2, capítulo 2, parágrafo 1 .

28 WEBER (1984) p.204.

${ }^{29}$ KANT (1967) pp. 101 y ss. de la edición original de 1787.
} 
“virtuosos", el deseo de autoaprobación ${ }^{30}$. Cuando ese límite es violado por otra persona, se produce el "resentimiento" tanto en el espectador como en la víctima. Este es mayor en la medida en que el daño causado es más grande. El asesinato o los crímenes contra la integridad personal y el robo o hurto son los delitos que producen la mayor indignación, mucho mayor que el incumplimiento de los contratos. Estos tres parecen los tres tipos generales de "delitos" en la clasificación de Adam Smith, y su estudio parece que debería agotar la materia jurídica. [Sic!] Los castigos restauradores de la justicia serán mayores en proporción al resentimiento que el crimen haya causado ${ }^{31}$. La medida del castigo la da el resentimiento ${ }^{32}$, y la justicia judicial se reduce al sistema de castigos $^{33}$.

\section{B) El FIN PERSEGUIDO POR LA NATURALEZA}

Después de afirmar todas estas cosas, Adam Smith trata de determinar con qué fin la Naturaleza ha ordenado las cosas de la manera señalada. En esa tarea incurre en la típica contradicción "performativa" de los utilitaristas. En efecto, a pesar de que sostiene que la medida del castigo es un sentimiento natural y no un juicio prudencial que resulte de disquisiciones dialécticas, aduciendo que la Naturaleza nos ha dado a los hombres unas inclinaciones instintivas que nos ordenan a los fines y medios adecuados ${ }^{34}$, después de ello, pasa a explicarnos cuál es el fin por el que la Naturaleza ha ordenado así las cosas y cómo lo ha hecho. Pero si lo primero es verdad, la explicación o es imposible o es del todo superflua. En efecto, si nuestros sentimientos instintivos nos ordenan a los medios y fines adecuados, entonces parece inútil preguntarse para qué lo hacen y cómo. Si nos lo preguntamos y -sobre todo- si lo respondemos y lo exponemos, parecería que estamos o bien tratando de corregir lo que ha hecho la Naturaleza, o bien tratando de evitar que los hombres se desvíen de su orden. Mas, de nuevo, si nuestras inclinaciones instintivas están determinadas, tales correcciones o desviaciones deberían ser imposibles.

En cualquier caso, Smith pasa a explicarnos el orden natural. Según él, la Naturaleza [con mayúscula] tenía en miras la utilidad social cuando dispuso que los hombres sientan resentimiento frente a la injusticia que comenten otros y remordimientos frente a la injusticia que ellos mismos cometen (y no frente a las faltas de beneficencia o gratitud). Hay, en efecto, tres grados de conexiones entre individuos: el mejor es aquel

\footnotetext{
30 Por ejemplo, parte III, capítulo 3, parágrafo 4.

31 Parte II, sección 2, capítulo 2, parágrafo 2.

32 Parte II, Sección 1, capítulos 1, parágrafo 6; y 5, parágrafo 10.

33 Parte II, sección 2, capítulo 2, parágrafo 2. Inmediatamente después trae Adam Smith un párrafo en el que estudia la naturaleza del "remordimiento". En este pasaje se puede apreciar la metafísica antropocéntrica de que adolece Smith: la medida ya no es Dios, el juez ya no es Dios (como en Platón y como es razonable), la medida es los sentimientos de los hombres, de las "criaturas racionales". El remordimiento smithiano se produce de diversos sentimientos, pero todos tienen que ver exclusivamente con los otros hombres o con la sociedad. Después añade otro párrafo acerca de los sentimientos de autoaprobación del hombre justo. Allí la alegría aristotélica del hombre maduro ante el recuerdo de sus nobles acciones se convierte en la autoaprobación y el "autoaplauso", en el mejor de los casos, de un hombre timocrático en el sentido del libro VIII de la República.

34 Parte II, sección 1, capítulo 5, parágrafo 10. Esta doctrina se confirma, como explicaremos, en el capítulo 3 de la sección 2 de la Parte II.
} 
en el que los miembros de la sociedad se prestan mutuo auxilio por amor, gratitud, amistad y estima. Este tipo de sociedad es feliz y pleno. Un segundo grado es aquel en el que el mutuo auxilio no se presta por esos nobles motivos, sino por el sentido de su utilidad, sin amor ni afecto mutuos. Este segundo grado existe, por ejemplo, en una sociedad de mercaderes. Este otro tipo de sociedad, aunque pueda subsistir, no es tan dichoso ni tan agradable como el primero. En el tercer grado y más bajo, en cambio, la sociedad no puede subsistir. Si los hombres se dañan mutuamente a cada paso no pueden vivir juntos. Aun en una sociedad de ladrones y asesinos los miembros deben abstenerse de dañarse mutuamente. Se ve, entonces, que la justicia smithiana es más necesaria a la sociedad que la beneficencia, también smithiana. Nuestros naturales resentimiento o remordimiento frente a la injusticia son, por tanto, los grandes protectores de la asociación humana ${ }^{35}$.

\section{C) TEORÍA DE LA ACCIÓN HUMANA Y DEL CASTIGO JURÍDICO}

Hemos de preguntarnos ahora, con Adam Smith, qué tipo de injusticia es castigada en la sociedad. Para responder a esta pregunta, veamos cómo el autor escocés comienza haciendo algunas importantes observaciones acerca de la acción humana.

La acción, dice, se compone de “intención o afecto del corazón”, de donde procede; movimiento del cuerpo, ocasionado por la intención; y consecuencias que de hecho se siguen del movimiento corporal. Según Smith, los dos últimos elementos no deberían fundar ninguna alabanza o censura. La acción corporal, en efecto, nos dice Smith, puede ser la misma en acciones meritorias o censurables, como "tirar del gatillo", que resulte en cazar un pájaro o asesinar a un hombre. Las consecuencias deberían ser aún más indiferentes para la alabanza o la censura, pues dependen de la fortuna. Solo las consecuencias que entren en la intención o que muestren alguna cualidad agradable o desagradable del corazón deberían dar lugar a responsabilidad. Sin embargo, no es así. Como ya tuvimos ocasión de mencionarlo, la fortuna tiene un papel en el mérito o la censura, en la justificación de una alabanza o de un castigo, según Adam Smith.

El párrafo anterior es probablemente un claro reflejo de la influencia del calvinismo en Smith. En efecto, en la ética calvinista lo único que importa es la unión interior con la "Voluntad de Dios": "El cristiano obra bien y deja el resultado en manos de Dios”, como dice Max Weber ${ }^{36}$. Quizá esté también hondamente influido por el tipo de antropología a que dio lugar el cartesianismo. En efecto, se nota un marcado dualismo (no ontológico, puesto que Smith es materialista). Esto, quizá, pueda entenderse mejor si se pone en contraste con la teoría clásica.

\footnotetext{
35 Parte II, sección 2, capítulo 3, parágrafos 1-4. En CASANOVA (2007) se muestra que es en este punto donde se conectan la Teoría de los sentimientos morales con la Riqueza de las naciones: de la prudencia depende el éxito en los negocios de este mundo; de la justicia y la beneficencia no depende el éxito, sino solo la estima de los hombres. Tienen razón tanto RAPHAEL y MACFIE (1984) pp. 20-25 de la introducción de los editores, como CARRASCO (2005) p. 29, en que no hay contradicción alguna entre estas dos obras de Adam Smith.

36 WeBER (1982) p. 355.
} 
En la teoría clásica, la acción exterior no es un mero "movimiento corporal", sino que está intrínsecamente informada por el fin inmediato del agente, y materializada en las circunstancias esenciales o accidentales en que se da. No es la acción exterior "tirar del gatillo", sino "cazar un pájaro" o "cometer homicidio". Por esto, aunque la intención mediata (lo que Smith llama "intención o afecto del corazón”) sea buena, la acción puede ser mala, si por falta de sabiduría práctica (prudencia) el "objeto" (el fin inmediato y las circunstancias esenciales) o las "circunstancias" (accidentales) son desproporcionados. Demos varios ejemplos. Si quiero ayudar a los pobres pero para ello robo, entonces mi intención es buena, pero mi objeto malo, por ser desordenado el fin inmediato y por violar el orden de la justicia conmutativa (que Smith desconoce). Si, siendo cirujano, quiero curar a un paciente pero por impericia lo mato, mi acción tiene un fin mediato bueno y un fin inmediato también bueno, pero el segundo no informa mis movimientos corporales en la situación concreta, por una razón que me es imputable. De nuevo, si quiero concretar el amor fecundo a una mujer y si esa mujer es mi esposa, mis relaciones sexuales con ella serían en principio buenas. Pero si tratara de tenerlas en una plaza pública a plena luz del día la acción sería mala a causa de las circunstancias (aparentemente accidentales) que la acompañan. Si la mujer no es mi esposa, la acción es mala a causa de circunstancias esenciales: el objeto es malo y el acto es o bien adulterio o bien fornicación.

Como se ve, la distancia entre Smith y la teoría clásica de la acción externa es enorme. Esta brecha se revela como aún más grande si consideramos que las "consecuencias" no son lo que define a una acción como buena o mala desde el punto de vista clásico. Sin embargo, como hemos visto, en ese mismo punto de vista hay un orden en el mundo y en la sociedad que debe ser descubierto y respetado ${ }^{37}$. Si alguien, por tanto, transgrede ese orden, esa persona tendrá que reparar el daño. Pero también, en la materia que nos ocupa ahora, ese orden tiene exigencias para el reparto de bienes y males exteriores y para la igualdad en las transacciones que tienen títulos diferentes a las acciones voluntarias de las partes. Por ello, en el plano de la justicia conmutativa, a menudo la reparación no consiste en un "castigo", sino en una "indemnización". No se trata de que se penalicen unas "consecuencias" no intentadas ${ }^{38}$, sino o bien de que ha habido una violación del medio real de la igualdad en las transacciones o bien de que la prudencia judicial puede considerar equitativo que una parte, más bien que otra, cargue con ciertos daños, como ya se explicó más arriba.

37 Por cierto que el Max Weber de La política como vocación implícitamente acepta que hay un orden real desde el que se pueden juzgar las ideologías. Este aspecto de su obra, quizá el más importante de todos, es con frecuencia omitido por insignes ideológos que usan a Weber para atacar a la Iglesia Católica y su afirmación rotunda de que existe un orden natural.

${ }^{38}$ Hay un punto, con todo, en el que verdaderamente la responsabilidad penal puede verse agravada por las consecuencias de una acción delictuosa o de una tentativa criminal. En ese solo punto lo que dice Smith conserva cierta verosimilitud. Algunos códigos de Derecho Penal han establecido que si alguien, por ejemplo, intenta lesionar gravemente a una persona, pero le produce la muerte más allá de la intención (y de la causalidad normal, incluso), debe el perpetrador ser castigado con una pena mayor que la que corresponde a la solas lesiones. Tal sería el caso si, queriendo el criminal cortar el brazo a una persona, y realizando esa acción con pericia quirúrgica, la víctima muriera por tener un corazón débil. Se trata de los llamados delitos preterintencionales. 
Adam Smith negaría lo que se ha dicho en el párrafo anterior, porque allí se supone que un juez o un ser humano, en general, puede captar en lo sensible y concreto "lo que es justo". Es decir, allí se supone tanto que hay captaciones inteligibles de una cierta medida también inteligible que se halla en lo sensible; como que esas captaciones pueden ordenar nuestra acción exterior para servir de modo consciente un orden real. Adam Smith niega esto. Como sucedáneo propone un puro naturalismo, una nueva "cosmología" en la que la sabiduría y la prudencia ya no sean necesarias. Veamos este último punto.

\section{LA COSMOLOGÍA NATURALISTA Y MECANICISTA}

En la parte II, sección 2, capítulo 3 Adam Smith sostiene que las causas final y eficiente deben ser bien distinguidas. Acto seguido dice que sería absurdo pensar que la causa final tiene alguna importancia en la explicación de los fenómenos biológicos, tales como la digestión o la circulación. Tales fenómenos, dice, ocurren sin que la sangre o la comida intenten el fin al que están dirigidos. Inmediatamente compara estos casos con los engranajes de un reloj. La intención, en el reloj y en los fenómenos biológicos, ha de atribuirse al hacedor, no a los agentes particulares. Luego pasa Smith, el utilitarista, a aplicar estas observaciones al orden social. (final del parágrafo 5) ${ }^{39}$ :

Pero aunque al explicar las operaciones de los cuerpos nunca dejamos de hacer esta distinción entre la causa eficiente y la final, al explicar las operaciones de la mente estamos muy dispuestos a confundir estas dos cosas tan distintas. Cuando somos conducidos por principios naturales a fomentar los mismos fines que nos recomendaría una razón ilustrada y refinada, estamos muy inclinados a imputar a una tal razón, como a su causa eficiente, los sentimientos y las acciones por las cuales se fomentan tales fines y a imaginarnos que pertenece a la sabiduría del hombre lo que en realidad pertenece a la sabiduría de Dios.

\section{A) OBJECIÓN DE PRIMER GRADO. RESPUESTA}

Después de hacer afirmaciones tan sorprendentes y contrarias a cualquier experiencia, pero exigidas por presupuestos nominalistas y por un cierto apego a los hábitos recibidos por tradición, Smith intenta disipar las dudas que las objeciones más obvias podrían suscitar. La más importante de tales objeciones es que la consideración de la utilidad social parece jugar un papel preponderante en el establecimiento del sistema punitivo, mucho más central que cualquier sentimiento. Muy probablemente contra Hume, Adam Smith sostiene que aunque la existencia de la sociedad dependa de una

\footnotetext{
39 Es probable que tenga razón FLEISCHACKER (1991) pp. 149-169, cuando afirma que Adam Smith es un precedente que tuvo influencia en la formulación kantiana del imperativo categórico. Sin embargo, creo que se equivoca cuando afirma que el espectador imparcial smithiano y el imperativo kantiano tienen el mismo propósito (pp. 263-264). Aunque es verdad que Smith distingue la justicia o el deber, por una parte, de la prudencia, por otra, sin embargo, todavía la argumentación con la que él trata de mostrar la "razonabilidad" de nuestros "sentimientos naturales" conectados con la justicia se basa en razones de utilidad (por ejemplo, SMITH (1984), Parte VI, Sección 2, Introducción, parágrafo 1).
} 
observancia tolerable de la justicia, no es esta consideración lo que lleva a establecer el sistema de castigos que ha de imponerse a los violadores de la ley. Con una ingeniosa manera de expresarse, nuestro autor sostiene que nuestras reacciones o sentimientos naturales son la causa inmediata del sistema penal o jurídico, y que la sabiduría de la que dependen tales reacciones pertenece no a los hombres, sino a la Naturaleza o a su Autor $^{40}$ (parágrafos 6-7):

Con frecuencia oímos que los jóvenes y los licenciosos ridiculizan las más sagradas reglas de la moral, y profesan las máximas más abominables de conducta, a veces por corrupción, pero más a menudo por la vanidad de sus corazones. Nos llenamos de indignación y ardemos en deseos de refutar y desenmascarar tales principios detestables. Pero aunque es su odiosidad intrínseca lo que origina nuestra inflamada oposición contra ellas, no estamos dispuestos a reconocer que es esta la sola razón por la que las condenamos [...]. La razón, pensamos, no parecería concluyente. Pero, ¿por qué no lo sería? Las odiamos y detestamos porque son objeto natural de odio y desprecio (parágrafo 8).

Como se ve, los hábitos buenos por los que una persona "decente" (como el Céfalo de República) reacciona indignada ante la sofística son objeto de amor por parte de nuestro antiguo calvinista. Pero, como buen ex protestante, Smith piensa que la razón no puede fundar esos hábitos, y por ello viene a asemejarse a los "conservadores" atenienses (esos que condenaron a Sócrates y pensaron que en él estaban condenando a la sofística), con la importante diferencia de que el escocés rechaza a Dios como medida.

Como si el pasaje anterior no fuera suficientemente claro, nuestro autor arrojará mucha más luz sobre este punto de la irrelevancia de la razón en el diseño del sistema penal. Afirma, en efecto, que aunque no se requiere de mucho acumen para darse cuenta de la tendencia destructora del bienestar social que tienen las prácticas licenciosas, casi nunca es tal consideración lo que nos dispone contra tales prácticas. Más aún nunca es tal consideración lo que originalmente nos dispone. En efecto, nuestra preocupación por el individuo no surge de la preocupación por la sociedad ni de nuestra preocupación por la multitud. Al contrario, es nuestra preocupación por la multitud lo que está compuesto "de la preocupación particular que sentimos por los diferentes individuos de los que se compone". Y es de la preocupación por el individuo de donde surge de modo natural el resentimiento que también de modo natural y sin necesidad de consideraciones dialécticas mueve a castigar un crimen.

\section{B) ObJeCiOnes de SEgundo gRAdo. Respuestas}

Para poder sostener este principio, Adam Smith sale al paso de dos posibles objeciones. La primera consistiría en que una persona civilizada entiende que la pena ha de aplicarse también cuando la víctima de un crimen nos resulta odiosa. Contra tal objeción aduce que hay un sentimiento que abarca a todos nuestros "fellow-creatures",

\footnotetext{
40 Adam Smith evoluciona en el punto relativo a la concepción del Ser supremo. Ya se dijo que en la primera edición él sigue siendo cristiano o aparentando serlo. Más tarde pueden verse claros rasgos de deísmo. Pero en muchos pasajes parece más bien suscribir una visión spinozista: "Deus, sive Substantia, sive Natura".
} 
un sucedáneo sentimental de la boúlesis aristotélica y que no necesita de una intelección previa, sino de un "orden natural":

Ha de observarse, sin embargo, que esta preocupación no necesariamente incluye en sí ningún grado de esos exquisitos sentimientos que llamamos comúnmente amor, estima y afecto, y por el que distinguimos a nuestros particulares amigos y conocidos. La preocupación que se requiere para esto no es más que el general fellow feeling que tenemos con cualquier ser humano por el mero hecho de que es nuestra cocriatura. Entramos en el resentimiento aun de una persona odiosa, cuando es dañada por aquellos a los que no ha provocado previamente. Nuestra censura de su carácter y conducta ordinarios no impide del todo en este caso nuestro cosentir su natural indignación, aunque dicha censura pueda muy bien empañar el cosentimiento de aquellas personas que no son extremadamente honradas o que no han sido acostumbradas a corregir o regular sus sentimientos naturales por medio de reglas generales (parágrafo 10) ${ }^{41}$.

La segunda consistiría en que claramente hay crímenes en los que la consideración de la utilidad social es la única causa que fundamenta una pena; pena que podría repugnar a nuestros sentimientos de humanidad si no fuera por la necesidad pública. Contra esta objeción usa dos argumentos. Primero aduce que los crímenes en que la consideración de la utilidad social es la verdadera guía del castigo son una excepción. Pero su previo razonamiento lo ha hecho capaz de integrar esta preocupación por la sociedad en su sistema sentimental, pues aquella estaría compuesta de los naturales sentimientos que hay en nuestro pecho por otros individuos. El artificio contractualista que es la sociedad puede gozar de una reverberación de las pasiones que se suscitan naturalmente en nosotros:

En algunas ocasiones, en verdad, castigamos o aprobamos el castigo solo por una consideración del interés general de la sociedad que, nos imaginamos, no puede asegurarse de otra manera. De este tipo son los castigos que se infligen por una violación de lo que se llama o bien policía civil [civil police] o bien disciplina militar. Tales crímenes no lesionan inmediata o directamente a persona particular alguna; pero sus consecuencias remotas, se supone, producen o pueden producir graves inconvenientes o graves desórdenes en la sociedad. [...] Cuando la preservación de un individuo es incompatible con la seguridad de la multitud, nada puede ser más justo que el que se prefiera los muchos a uno solo" (parágrafo 11).

El segundo argumento contra la posible segunda objeción consiste en decir que la Naturaleza nos ha enseñado a esperar [hope], y la religión -pensamos- nos autoriza a tener como cierto [expect $]^{42}$ que las injusticias de esta vida serán castigadas en la venidera, aun cuando dicho castigo ya no sería beneficioso a la sociedad.

\footnotetext{
41 Para evitar aquí una franca contradicción (pues se está sosteniendo que la base de las reglas generales es este sentimiento natural, al mismo tiempo que se dice que dicho sentimiento puede ser empañado si no se acrisolan los sentimientos con reglas generales) habrá que decir que este sentimiento natural subsiste siempre o generalmente.

${ }^{42}$ Es en este pasaje donde claramente se manifiesta el abierto abandono del cristianismo por Adam Smith. En las ediciones 1 y 2 había él escrito que la religión nos autoriza a tener como cierto el castigo en la otra vida. Después añadió "pensamos". En las ediciones 1-5 decía que el cristianismo como revelación divina
} 


\section{C) Corolario}

Se ve así que la concepción de la justicia de Adam Smith está imbricada en un sistema cosmológico y metafísico mecanicista del tipo frecuente entre los autores postcartesianos de los siglos XVII y XVIII. En él, toda la realidad corpórea habría sido producida por un "relojero" de tipo deísta o por una Naturaleza de tipo spinozista ${ }^{43}$.Los seres humanos no tendrían propiamente hablando "sabiduría", sino que estarían dirigidos a sus fines naturales por esta fuerza supraindividual de la Naturaleza. Lo estarían también en lo concerniente a la justicia del juez, que sería el resultado mecánico del resentimiento natural que producirían los crímenes. Pero debe acotarse que ese "resentimiento natural" toma forma concreta solo en el trato social, gracias a las reacciones de aprobación o censura de nuestros prójimos. Nada más alejado de la cosmología, antropología y filosofía política y moral aristotélicas, a las que Descartes y los "postcartesianos" se opusieron de intento.

\section{BIBLIOGRAFÍA CITADA}

AQUino, Tomás de, In Decem Libros Ethicorum Expositio.

AQUINO, Tomás de, Summa Theologiae I-II y II-II.

ARISTÓTEles, Ética a Nicómaco.

CARrasco, Alejandra (2005): “Teoría moral de Adam Smith”, Seminarios de filosofía, vol. XVII-XVIII: pp. 27-41.

CASANOva, Carlos (2005): "Nominalismo jurídico, escolástica española y tradición republicana”, Dikaiosyne (Mérida -Venezuela-, Universidad de los Andes) año VIII, No 15: pp. 59-74.

nos mostraba algo sobre la vida venidera. Aquí suprime este largo pasaje y añade: "En toda religión, y en toda superstición que ha visto el mundo, por ello, ha habido un Tártaro tanto como un Elíseo, un lugar donde se castiga al malo y se premia al justo" (SMITH (1984) p. 91). En otro trabajo tuvimos ocasión de mostrar que Adam Smith piensa que el alma no es inmortal, pero sostiene que la creencia en la inmortalidad es útil para la sociedad.

43 El mecanicismo de Adam Smith solo se sugiere en el pasaje sometido a análisis con la ilustración de las partes del reloj. Pero es explícito en otros pasajes, tales como: parte I, sección 1, capítulo 4, parágrafo 2; y parte VII, sección 2, capítulo 1, parágrafos 37 y 43-47. En el segundo texto, en un comentario a un pasaje de Marco Aurelio, Adam Smith parece aceptar que los seres humanos están situados en cadenas causales que son infinitas tanto "hacia arriba" (en la dirección de las causas, sin que haya una primera) como "hacia abajo” (en la dirección de los efectos, sin que haya uno último). En esto se emparentaría Smith con Kant. En todo caso, en el segundo texto citado, Smith expresamente postula que los hombres están inmersos en la causalidad de la Naturaleza y que ni aun sus sentimientos interiores están sustraídos a ella, contra lo que pensaban los antiguos estoicos. A pesar de ello, Smith afirma allí que los razonamientos de las escuelas de filosofía afectan el juicio del espectador imparcial que mora en nuestro pecho, y con ello parece postular que hay algo fuera de la cadena causal natural. Esto no es más que una ilusión, porque la medida de la propiedad moral la pone Smith, en último término, en los sentimientos simpatéticos del espectador imparcial y bien informado (parágrafo 49), es decir, en la sociedad y los efectos de la acción de esta sobre nuestros sentimientos naturales, entre los que se cuentan el deseo de agradar a nuestros espectadores y el deseo de ser en verdad lo que es agradable, deseo este que se identifica con el de "autoaprobación". Pero este punto ya se ha mostrado suficientemente en CASANOVA (2007). 
Casanova, Carlos (2005): "Nominalismo jurídico, escolástica española y tradición republicana". Disponible en: < http://www.puc.cl/iapuc/>, dentro de las ventanas "quiénes somos", “investigación” [fecha de consulta: mayo 2007].

Casanova, Carlos (2007): “Adam Smith: Champion of Freedom?”, Jogelméleti Szemle. Disponible en: < http://jesz.ajk.elte.hu/casanova29.mht >.

CICERÓN, Tópicos.

FleisCHACKER, Samuel (1991): "Philosophy in Moral Practice: Kant and Adam Smith", en: Kant Studien, 82, pp. 249-269.

GAYO, Institutas.

HAYEK, Friedrich (1960): The Constitution of Liberty (Chicago, The University of Chicago Press).

HAYEK, Friedrich (1976): The Road to Serfdom (Chicago-Londres, The University of Chicago Press).

HAYEK, Friedrich (1980a): "Individualism: True and False", en: Individualism and Economic Order (Chicago-Londres, The University of Chicago Press) pp. 1-32.

HAYEK, Friedrich (1980b): “Free” Enterprise and Competitive Order", en: Individualism and Economic Order (Chicago-Londres, The University of Chicago Press) pp. 107-118.

HAYEK, Friedrich (1981): "Economía, ciencia y política", en: Camino de libertad (Santiago de Chile, Centro de Estudios Públicos) pp. 145-168.

JONES, Michael (2004): The Slaughter of Cities. Urban Renewal as Ethnic Cleansing. (South Bend, Saint Augustine Press) 668 pp.

KanT, Immanuel (1967): Kritik der Praktischen Vernunft (Hamburgo, Verlag von Felix Meiner) $200 \mathrm{pp}$.

Platón, República.

Platón, Teeteto.

PLATÓN, Leyes.

Smith, Adam (1984): Theory of Moral Sentiments (Daivid Daiches RaPHAEL y Alec Lawrence MACFIE (eds.), Indianápolis, Liberty Fund) 412 pp.

Tocqueville, Alexis de (1953): Democracy in America (Nueva York, Alfred Knopf) vol. I.

VIEHWEG, Theodor (1964): Tópica y jurisprudencia (Madrid, Ediciones Taurus) 143 pp.

VILlEY, Michel (1981): Compendio de filosofía del Derecho (Pamplona, EUNSA) 2 volúmenes.

Villey, Michel (1969): Seize Essais de Philosophie du Droit (París, Dalloz) p. 193.

Weber, Max (1984): La ética protestante y el espiritu del capitalismo (Traducc. Luis LEGAZ LaCAMbra, Madrid, Sarpe) 227 pp.

WeBER, Max (1982): “La política como vocación”, en: Max Weber. Escritos políticos. (México, Folios Ediciones, S. A., vol. 2) pp. 308-364. 